\title{
Comment on: Krabbe KS, Nielsen AR, Krogh-Madsen $R$ et al (2007) Brain-derived neurotrophic factor (BDNF) and type 2 diabetes. Diabetologia 50:431-438
}

\author{
G. N. Chaldakov • A. B. Tonchev • L. Manni • \\ M. G. Hristova • V. Nikolova - M. Fiore • D. Vyagova • \\ V. N. Peneva • L. Aloe
}

Received: 13 February 2007 / Accepted: 10 April 2007 / Published online: 2 June 2007

(C) Springer-Verlag 2007

\section{To the Editor:}

Some men see things as they are and say: 'Why?' I dream things that never were and say: 'Why not!'

\section{J. F. Kennedy}

In a recent issue of Diabetologia Karen Krabbe et al. [1] reported that low plasma levels of brain-derived neurotrophic factor (BDNF) are associated with impaired glucose metabolism in type 2 diabetes, providing a set of supporting data [1], including one of our papers demonstrating reduced plasma levels of both nerve growth factor (NGF) and BDNF in patients with acute coronary syndromes [2]. Thus, Krabbe et al. concluded that decreased BDNF levels (both circulating and those released from brain) may be involved not only in the pathogenesis of dementia and depression [1], but also in diabetes.

G. N. Chaldakov $(\bowtie) \cdot$ A. B. Tonchev $\cdot$ V. N. Peneva

Division of Cell Biology, Medical University,

Varna, Bulgaria

e-mail: chaldakov@yahoo.com

L. Manni $\cdot$ M. Fiore $\cdot$ L. Aloe

Institute of Neurobiology and Molecular Medicine, NGF Section,

CNR-European Brain Research Institute Rita Levi-Montalcini,

Rome, Italy

\section{G. Hristova}

Department of Endocrinology, Polyclinic,

Asparuhovo,

Varna, Bulgaria

V. Nikolova $\cdot$ D. Vyagova

Department of Intensive Cardiology Unit,

University St Marina Hospital,

Varna, Bulgaria
Today, the 'classical' neurotrophins NGF and BDNF are increasingly considered not only neurotrophic factors, but also immunotrophins, epitheliotrophins [3] and metabotrophins (metabotrophic factors) $[4,5]$. Indeed, NGF and BDNF are found in reduced systemic and/or local levels in cardiometabolic diseases such as coronary atherosclerosis, metabolic syndrome and type 2 diabetes [3-5], including various diabetes-associated disorders, such as skin ulcers [3] and erectile dysfunction [6]. Altogether, these data were conceptualised as a metabotrophin-deficit hypothesis of cardiometabolic disease, suggesting novel roles for NGF and BDNF in metabolic and vascular health and disease, that is, their metabotrophic potentials, including the improvement of glucose, lipid and antioxidant metabolism $[3,4]$. Accordingly, increased BDNF circulating levels documented in cardiometabolic disease [7-9] might be considered a protective phenomenon. Of note: (1) wounded diabetic skin reveals increased levels of NGF, whereas a local treatment with NGF benefits the healing process; and (2) experimentally induced cardiac ischaemia upregulates local NGF levels, whereas exogenously administered NGF improves the cardiac function [3].

Conceptually, both NGF and BDNF are, in analogy to Rita Levi-Montalcini's semantics of neurotrophic factors, designated metabotrophic factors (see text box), a group that also includes adiponectin, interleukin 10, ciliary neurotrophic factor, glial cell line-derived neurotrophic factor and leukaemia inhibitory factor [4]. We hypothesised that stimulation of secretory and/or signalling pathways of metabotrophic factors may provide a novel class of drugs in cardiometabolic disease [2-4]. Likewise, one may suggest that sibutramine (a popular anti-obesity drug of the group of serotonin and noradrenaline [norepinephrine] reuptake inhibitors, originally developed as an antidepressant) may, 


\section{Metabotrophic potential of NGF and BDNF}

NGF and BDNF are synthesised and released from pancreatic beta cells

NGF and BDNF exert insulinotropic effect

NGF and BDNF are protective for the islets of Langerhans

BDNF improves glucose and lipid profile in experimental diabetes

NGF upregulates expression of LDL receptor-related protein

NGF upregulates expression of PPAR- $\gamma$

NGF exerts antioxidant effect

NGF and BDNF suppress food intake

NGF improves experimentally induced cardiac ischaemia

BDNF-deficient mice develop metabolic abnormalities similar to the metabolic syndrome

An atherogenic diet decreases brain BDNF levels

Energy restriction increases brain BDNF levels and improves the metabolic profile in experimental metabolic syndrome

\section{Diseases}

\section{Reduced NGF and/or BDNF levels*}

Coronary atherosclerosis

Heart failure*

Acute coronary syndromes*

Type 2 diabetes*

Diabetic neuropathy

Diabetic erectile dysfunction

Metabolic syndrome

Obesity

Bulimia nervosa

Anorexia nervosa

* There are, however, reports showing elevated circulating levels of BDNF [7-9]

via an increased BDNF brain level [4], mediate its antiobesity effect. Consistent with this hypothesis are results showing that mutations affecting $B d n f$ (the gene encoding
BDNF) in mice or NTRK2 (the gene encoding the highaffinity BDNF receptor TrkB) in an 8-year-old boy are associated with hyperphagia and severe obesity [4].

Further studies in the adipobiology and adipopharmacology of metabotrophic factors [4] and the role of platelets in the regulation of circulating BDNF levels [10] might support today's promising situation of potential roles of NGF and BDNF in cardiometabolic biology and pharmacology. Why not?

\section{References}

1. Krabbe KS, Nielsen AR, Krogh-Madsen R et al (2007) Brain-derived neurotrophic factor (BDNF) and type 2 diabetes. Diabetologia 50:431-438

2. Manni L, Nikolova V, Vyagova D, Chalakov GN, Aloe L (2005) Reduced plasma levels of NGF and BDNF in patients with acute coronary syndromes. Int J Cardiol 102:169-171

3. Chaldakov GN, Fiore M, Stankulov IS et al. (2004) Neurotrophin presence in human coronary atherosclerosis and metabolic syndrome: a role for NGF and BDNF in cardiovascular disease? Prog Brain Res 146:279-289

4. Chaldakov GN, Fiore M, Tonchev AB, Aloe L (2006) Adipopharmacology, a novel drug discovery approach: a metabotrophic perspective. Lett Drug Des Discov 3:503-505

5. Geroldi D, Minoretti P, Emanuele E (2006) Brain-derived neurotrophic factor and the metabolic syndrome: more than just hypothesis. Med Hypotheses 67:195-196

6. Chen Y, Yang R, Yao L, Sun Z, Wang R, Dai Y (2007) Differential expression of neurotrophins in penises of streptozotocin-induced diabetic rats. J Androl 28:306-312

7. Cai D, Holm JM, Duignan IJ et al (2006) BDNF-mediated enhancement of inflammation and injury in the aging heart. Physiol Genomics 24:191-197

8. Ejiri J, Inoue N, Kobayashi S et al (2005) Possible role of brainderived neurotrophic factor in the pathogenesis of coronary artery disease. Circulation 112:2114-2120

9. Suwa M, Kishimoto H, Nofuji Y et al (2006) Serum brain-derived neurotrophic factor level is increased and associated with obesity in newly diagnosed female patients with type 2 diabetes mellitus. Metabolism 55:852-857

10. Lommatzsch M, Virchow JC (2006) Letter regarding article by Ejiri et al, 'Possible role of brain-derived neurotrophic factor in the pathogenesis of coronary artery disease.' Circulation 113: e724 